\title{
Evolutionary genetics of fluctuating asymmetry in the peacock butterfly (Inachis io)
}

\author{
J ACK J . WINDIG* \\ Department of Biology, University of Antwerp (UIA), Universiteitsplein 1, 2610 Antwerpen, Belgium
}

\begin{abstract}
Fluctuating asymmetry (FA) and trait size were analysed for two pupal and two adult traits in the peacock butterfly (Inachis io L.). Natural families were raised in the field and the laboratory. The amount of FA relative to trait size was lower for the measured pupal traits. Although there were clear differences in trait sizes between the sexes and between the laboratory and field, no differences in FA were detected. Individuals that died in the pupal stage or hatched with crippled wings did not differ in their amount of FA from healthy adults. Differences for the trait sizes between families were large and significant and the heritabilities $\left(h^{2}\right)$ were high. For FA most differences between families were not significant and $h^{2}$ s were close to and not different from 0 . Only for one of the pupal traits was a significant difference detected between families but its $h^{2}(0.15)$ was not significantly different from 0. Differences in survival between families were not related to their average FA. Although half of the phenotypic correlations between trait sizes were significantly different from 0 , only one correlation between FA (for the adult traits) was significant, albeit weakly $(r=0.11)$. Some of the genetic correlations between trait sizes were strong and significant, but genetic correlations between FA were practically absent because of the low amounts of genetic variation for FA. A purely random cause of FA seems more likely for these traits than any influence of sex, environment, quality or genes.
\end{abstract}

Keywords: butterfly, fluctuating asymmetry, genetic correlations, pupae, quantitative genetics, wing pattern.

\section{Introduction}

Fluctuating asymmetry (FA) has been the focus of a wide range of evolutionary and ecological studies. It can be defined as 'small random departures from anticipated bilateral symmetry' (Markow, 1995). The popularity of FA originates from the idea that it can be seen as a direct measurement of the (genetic) quality of an individual. The idea is that individuals of low quality are developmentally less stable and unable to develop traits with precisely one value, equal on the left and right sides. Studies using this concept have reported that asymmetrical individuals have reduced reproductive success (e.g. Wauters et al., 1996) or reduction in other fitness related traits, e.g. resistance to herbivory (Møller, 1995), that there is sexual selection against asymmetry, e.g. females

*Present address: Department of Zoology, Stockholm University, 10691 Stockholm, Sweden. E-mail: jack.windig@zoologi.su.se prefer mating with more symmetrical males (e.g. Møller, 1994), that asymmetry is negatively correlated with the level of (enzyme) heterozygosity (e.g. Mather, 1953) and that individuals exposed to high levels of stress show higher asymmetry (e.g. Parsons, 1990).

The link between FA and fitness is, however, 'not as consistent as some reviewers suggest' (Pomiankowski, 1997). Male mating success, for example, is not always associated with decreased FA (e.g. Ueno, 1994). Clarke (1993) concluded that there is little empirical support for an association between heterozygosity and FA. Some carefully controlled and well replicated experiments did not show an association between FA and inbreeding (e.g. Fowler \& Whitlock, 1994). If FA in all traits reflects the quality of individuals strong correlations between the FA of different traits within populations are expected. Often, however, the FA of traits within a population do not correlate with each other (e.g. Brakefield \& 
Breuker, 1996; see Palmer \& Strobeck, 1986 for a review). Markow (1995) pointed out that two assumptions must be met in order for developmental stability (FA) to be important for the evolutionary potential of populations: differences in FA must be associated with differences in fitness and FA and genotype must be related.

From an evolutionary viewpoint a genetic analysis of a trait is essential: if there is no genetic variation natural selection cannot directly change a trait and on the other hand strong selection may deplete genetic variation. The heritability $\left(h^{2}\right)$ of FA has recently been the focus of a controversial metaanalysis by Møller \& Thornhill (1997). Their overall conclusion that 'there is a significant additive genetic component to developmental stability (a mean $h^{2}$ of 0.27 )' was strongly criticized by others. There have been claims that not all data used were correct or correctly cited (Leamy, 1997; Markow \& Clarke, 1997; Palmer \& Strobeck, 1997; Whitlock \& Fowler, 1997). Many studies did not fulfil the criteria necessary in order to be able to speak confidently about $h^{2}$ of FA. These criteria include:

1 that the asymmetry is larger than the measurement error (Palmer \& Strobeck, 1997);

2 that the asymmetry pattern is fluctuating in type rather than directional (one of the sides is on average larger), or antisymmetry (Leamy, 1997; Markow \& Clarke, 1997; Palmer \& Strobeck, 1997);

3 if FA is related to trait size, that this size effect has to be removed (Palmer \& Strobeck, 1997);

4 that a breeding design has to be used that is able to distinguish between additive variance, dominance variance, maternal, common environmental and residual variance effects (Swaddle, 1997; Whitlock \& Fowler, 1997).

There have also been doubts about the usefulness and validity of testing for an overall value of $h^{2}$ (Leamy, 1997; Markow \& Clarke, 1997; Palmer \& Strobeck, 1997; Pomiankowski, 1997). Comparing the $h^{2}$ of different categories of traits should be more informative. Swaddle (1997) remarked that field estimates probably would give a different result from laboratory results. He also suggested the use of genetic correlations to establish if there is an overall $h^{2}$ of FA. A possible explanation for the lack of positive correlations between FA of different traits is that environmental influences may have obscured strong genetic correlations. An analysis of genetic correlations between FA of different traits has, however, never been performed. A possible genetic relationship between FA and fitness parameters (or any other parameter, e.g. stress) can also be obscured by environmental influences.
In this paper, asymmetry in the Peacock butterfly (Inachis io) for two pupal and two adult traits is analysed at the phenotypic as well as the genotypic level. Family groups were raised in the field and the laboratory. The following questions will be addressed.

1 Is FA related (phenotypically) to the growth environment and/or sex?

2 Is FA related (phenotypically) to hatching success as a measure of quality?

3 Is there heritable variation for the traits and for their FA?

4 Is FA related to environment, sex or survival (as a measure of quality) at the genetic level?

5 What are the phenotypic and genetic correlations between the traits and between their FA?

\section{Materials and methods}

\section{Organism and breeding design}

The peacock is one of the most common butterflies in Belgium. Females lay batches of 200-600 eggs on the leaves of the stinging nettle, Urtica dioica. The larvae live gregariously up to the fifth instar. The larval period takes about 4 weeks, of which about 12 days are spent in the last two instars (Pullin, 1986).

Groups of larvae (henceforth called families) were located in the field in the first week of June. Most larvae were in their second instar. In two families larvae were just at the start of the third instar. The relationships between members within families were later tested using DNA multilocus fingerprinting (following Saccheri \& Bruford, 1994). All group members were found to share both the father and mother (Windig, unpublished), and thus can be treated as full-sib families. The families were split into a laboratory group and a field group.

The field larvae were caged in sleeves of gauze around the food plants on which they were found. New nettles, growing nearby, were used when the original nettles were near depletion. Because larvae about to pupate moved from their food plants and escaped in large numbers, families were brought to cages from which they could not escape, with a jar with cut nettles, a few days before pupation. These cages were left outside until all adults had emerged and the remaining pupae had died.

The laboratory larvae were raised following the method of Pullin (1986), with some exceptions. They were raised in groups of two in Petri dishes until the start of the fifth stage after which they were raised singly. Natural daylight was used and temperature was a constant $20^{\circ} \mathrm{C}$. Cut leaves were used as food, 
and renewed every other day. Pupae were placed in small peat pots until emergence.

Directly after emergence all adults were killed by freezing, and stored at $-70^{\circ} \mathrm{C}$. Laboratory butterflies were stored together with their pupal case. For field butterflies it was not known which pupal case belonged to which butterfly, and most pupal cases were damaged too much for analysis, so no analysis of field pupae was undertaken.

Eleven families were raised this way. In the field seven of these were lost through human activities (e.g. mowing of food plants) or other causes (possibly plundering by birds). To increase the number of families in the field four additional families were raised exclusively in the field. So 15 families were raised of which seven were exclusively in the laboratory, four exclusively in the field and four split over field and laboratory. The final number of adults raised per family per environment varied from 20 to 128 . Because precision of measurement is essential for the analysis of FA (Palmer \& Strobeck, 1986) only undamaged, immaculate adults with, for the laboratory butterflies, intact pupal cases were analysed. For around half of the families only about 20 unblemished adults per environment were available, so 10 males and 10 females were analysed per family per environment, 40 individuals for those families raised both in field and laboratory.

\section{Traits analysed}

Two pupal and two adult traits were measured that were chosen only for ease and precision of measurement. In this way there was a quite distant relationship between two pairs of related traits. All traits were measured on the left and right side. The mean of the left and right measurements was used as trait size. $t$-tests were used to determine whether the average difference between left and right was different from 0 , indicating directional asymmetry. Fifty individuals were measured for a second time without knowledge of the first measurement, to analyse repeatability of FA measurements. Two-way ANOVAS were performed for these individuals, with sides (left and right) and individuals as factors (Palmer, 1994). If the interaction term in such an ANOVA is not significant this indicates that the FA measurements are not larger than the measurement error. If the side term is significant this indicates directional symmetry.

In the pupa (Fig. 1) the width of the sheath covering the proboscis (tongue), called the HAUSTELLUM, was measured at the level of a small wart on the front leg sheath. The width of a small dark spot close by this wart, PUPAL SPOT, was the second pupal trait analysed. The pupal traits were measured with a microscope fitted with a micrometer (Zeiss) at $\times 25$. On the adult wings the number of blue scales belonging to one of the four spots composing the large eyespot on the hind wing was counted (Fig. 1). The scales in the spot itself, CORE SCALES, defined as touching each other with at least one side, and the loose scales around the spot, SCATTER SCALES, were counted separately. Both counts were also added, TOTAL SCALES, in order to be able to eliminate asymmetries caused by scales belonging to the core in one wing and not in the other. In a few butterflies the larger part of the area was completely covered with blue scales and no core and scatter scales could be distinguished, so these are only included in the analysis of TOTAL SCALES.

Asymmetry was measured as the absolute difference between left and right. Sizes of the pupal traits were normally distributed and no relationships

(a)

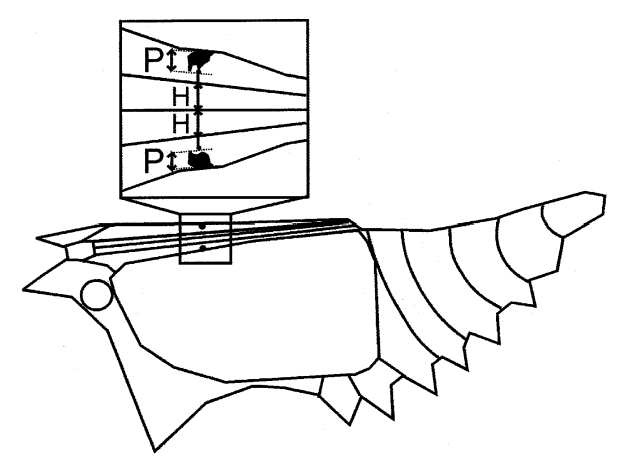

(b)

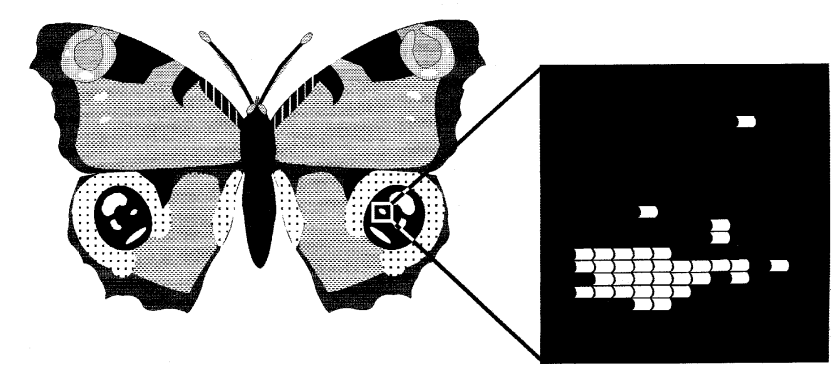

Fig. 1 Traits analysed in Inachis io. (a) Pupal traits. H, width of the segment covering the proboscis (HAUSTELLUM); P, width of spot (PUPAL SPOT). (b) Adult traits. Number of blue scales in core of part of eyespot (CORE SCALES) and number of 'loose' scales (SCATTER SCALES). In the drawing the numbers are 29 for CORE SCALES and 5 for SCATTER SCALES. 
existed between trait size and asymmetry (HAUSTELLUM, $r=0.121$; PUPAL SPOT, $r=-0.022$ ). Asymmetries were log-transformed for analysis to obtain normal distributions (Palmer \& Strobeck, 1986). The adult traits were log-normally distributed and asymmetry was positively related to trait size (CORE SCALES, $r=0.334$; SCATTER SCALES, $r=0.493$; and TOTAL SCALES, $r=0.441$; Fig. 2 ). To avoid effects of trait size when comparing asymmetries and to obtain normal distributions, the residuals of the regression line of log-transformed asymmetry on log-transformed trait size were used as a measure of FA (Fig. 2).

\section{Influence of environment and sex}

The influence of growth environment (laboratory, field) and sex on the trait sizes and their FA was analysed using two-way ANOvas. The influence of sex could be analysed for pupal traits only.

\section{Relationship with quality}

Quality was analysed for laboratory individuals using hatching success as a criterion. FA and trait means of the healthy individuals used in the rest of this study $(n=279)$ were compared with all individuals with an intact and measurable pupal case that had died in the pupal stage $(n=21)$ or that emerged as adults with crippled wings $(n=32)$. ANOvA was used to test for significant differences for the pupal traits. For the adult traits, individuals that died in the pupal stage were not available, and here $t$-tests were used to compare healthy and crippled adults.

\section{Genetic effects}

The total variation in a trait, phenotypic variation $\left(V_{\mathrm{P}}\right)$, can be divided into an additive variance component $\left(V_{\mathrm{A}}\right)$, and a nonadditive variance component, mostly the dominance variance component $\left(V_{\mathrm{D}}\right)$ and a residual variance component $\left(V_{\mathrm{R}}\right)$. When full-sibs are used, as in this study, $V_{\mathrm{A}}$ and $V_{\mathrm{D}}$ cannot be distinguished. The heritability $\left(h^{2}\right)$ in the strict sense is equal to $V_{\mathrm{A}} / V_{\mathrm{P}}$. In the case of a full-sib analysis a broad-sense $h^{2}$ is estimated where the numerator contains an extra $\frac{1}{2} V_{\mathrm{D}}$. In addition it can also contain part of maternal effects and common environmental effects.

Before the estimations of the variance components two-way ANOVAs were used with sex and family as factors. Variance components $\left(V_{\mathrm{A}}\right.$ and $\left.V_{\mathrm{R}}\right)$ and $h^{2}$ for trait sizes were estimated separately for left and right values. As these estimates were very similar only the means of these two estimates will be given. Genetic components for trait sizes were analysed for each environment and sex separately because their phenotypic values differed significantly for these factors. For the genetic analysis of FA all groups within families were pooled as no significant differences could be found between the groups. The variance components were estimated using a restricted error maximum likelihood (REML) procedure using the NF3 program of R. G. Shaw \& F. H. Shaw (Quercus: programs for quantitativegenetic analysis using maximum likelihood; published electronically on the Internet, available via anonymous ftp from ftp.bio.indiana.edu; directory path biology/quantgen/quercus) adapted for use on a personal computer. Significant differences of $V_{\mathrm{A}}$

Fig. 2 Relationship for Inachis io between size and asymmetry of total number of blue scales (see Fig. 1) before and after log-transformation. Fluctuating asymmetry is analysed as residuals of log-transformed values (vertical distance to regression line in right graph).
TOTAL NUMBER OF BLUE SCALES
UNTRANSFORMED

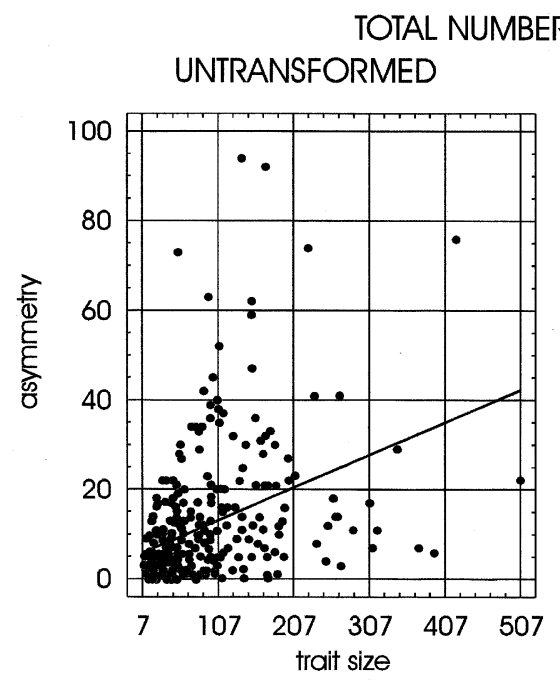

LOG-TRANSFORMED

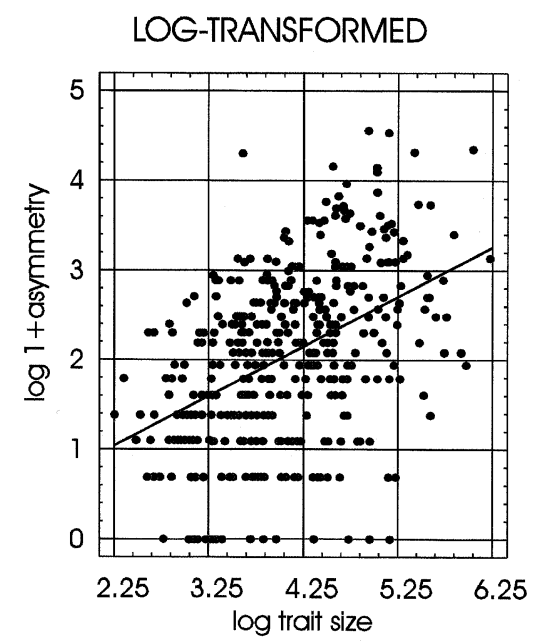


from zero were tested by comparing twice the difference of the maximum likelihoods of the full REML procedure and a REML procedure with the $V_{\mathrm{A}}$ restricted to zero with a $\chi^{2}$-distribution (Shaw et al., 1995).

\section{Genetic effects of quality}

To analyse whether FA is genetically related to quality, family means of FA were correlated to the percentage survival of the families in the laboratory. Because percentage survival cannot be determined on individuals, family means have to be used. The mean of a family approaches the breeding value of a genotype, and therefore the variation of the means approaches $V_{\mathrm{A}}$. It includes, however, part of $V_{\mathrm{D}}$ and $V_{\mathrm{R}}$, in our case with 10 individuals per family $22 / 40$ $V_{\mathrm{A}}+13 / 40 V_{\mathrm{D}}+1 / 10 V_{\mathrm{R}}$ (Windig, 1997). So a correlation using family means is an approximation of a genetic correlation. Survival percentage was arcsinetransformed prior to analysis to obtain a normal distribution.

The genetic effects of growth environment and sex were determined using three-way ANOvAs for the four families raised in both field and laboratory. Whether families differ in their sensitivity to the influences of environment or sex can be analysed by testing for significant interactions of family with environment or sex.

\section{Correlations}

Genetic correlations between trait sizes and between their FA were estimated using REML procedures with the NF3 program. Significant differences of $V_{\mathrm{A}}$ from zero were tested using the difference of the maximum likelihoods of the full REML procedure and a REML procedure with the $V_{\mathrm{A}}$ restricted to zero (Shaw et al., 1995).

\section{Results}

For all traits, left and right were the same size on average and the difference between them was larger than the measurement error (Table 1). Left-Right values closely followed a normal distribution without any indications of antisymmetry. The FA was about 50-60 per cent of the trait size for adult traits (Table 2), and 2-4 per cent for pupal traits. The value for TOTAL SCALES was slightly lower than for CORE and SCATTER SCALES indicating that some core scales on one wing had corresponding scales on the other wing belonging to scatter scales. The percentages for the adult traits were calculated on the log-transformed values. The percentages calculated on untransformed values were about half as large, but still much higher than for the pupal traits. The FA for PUPAL SPOT was about twice as large as that for the HAUSTELLUM.

\section{Influence of environment and sex}

Sex did not influence the size of the PUPAL SPOT (Table 2). Females, however, had a larger HAUSTELLUM and more blue scales, both CORE SCALES and SCATTER SCALES, in the adult eyespot. The FA of the pupal traits did not differ between the sexes. Females had slightly higher FA for the adult traits, but these were not significant when corrected for trait size.

The eyespots of butterflies raised in the field had significantly more blue scales than those raised in the laboratory (Table 3 ). This was caused by more SCATTER SCALES, whereas there were significantly fewer CORE SCALES in field butterflies. The difference between the laboratory and the field was the same for both sexes (no significant interaction, Table 3). The average FA differed somewhat between the field and laboratory (Table 2), but when

Table 1 Mixed-model two-way ANovAs analysing reliability of FA measurements in Inachis io. Fifty individuals were measured twice; absence of significant values for sides (left and right) indicates no directional asymmetry, significant values for the interaction terms indicate that individual differences between left and right $(=$ FA $)$ are larger than measurement error

\begin{tabular}{|c|c|c|c|c|c|c|c|c|c|c|}
\hline & \multicolumn{3}{|c|}{ Individuals } & \multicolumn{3}{|c|}{ Sides } & \multicolumn{3}{|c|}{ Individuals $\times$ sides } & \multirow[b]{2}{*}{ Error } \\
\hline & MS & $F_{49,100}$ & $P$ & MS & $F_{1,100}$ & $P$ & MS & $F_{49,100}$ & $P$ & \\
\hline HAUSTELLUM & 62.38 & 2.83 & 0.002 & 37.03 & 1.61 & 0.207 & 22.999 & 11.85 & $<0.0001$ & 1.856 \\
\hline PUPAL SPOT & 86.93 & 6.53 & $<0.0001$ & 17.96 & 1.35 & 0.248 & 13.307 & 5.99 & $<0.0001$ & 2.218 \\
\hline CORE SCALES & 1.0644 & 10.46 & $<0.0001$ & 0.2138 & 2.10 & 0.15 & 0.1018 & 64.18 & $<0.0001$ & 0.0016 \\
\hline SCATTER SCALES & 3.214 & 29.93 & $<0.0001$ & 0.1727 & 1.61 & 0.203 & 0.1073 & 20.29 & $<0.0001$ & 0.0053 \\
\hline TOTAL SCALES & 2.313 & 52.08 & $<0.0001$ & 0.0875 & 1.97 & 0.163 & 0.0444 & 54.60 & $<0.0001$ & 0.0008 \\
\hline
\end{tabular}


Table 2 Means of trait sizes and fluctuating asymmetry (FA) in Inachis io. Asymmetry of adult traits not corrected for size

\begin{tabular}{|c|c|c|c|c|c|c|c|c|c|c|c|c|}
\hline & \multicolumn{6}{|c|}{ Laboratory } & \multicolumn{6}{|c|}{ Field } \\
\hline & \multicolumn{3}{|c|}{ Male } & \multicolumn{3}{|c|}{ Female } & \multicolumn{3}{|c|}{ Male } & \multicolumn{3}{|c|}{ Female } \\
\hline & Mean & FA & $\%$ & Mean & FA & $\%$ & Mean & FA & $\%$ & Mean & FA & $\%$ \\
\hline HAUSTELLUM & 44.90 & 1.072 & 2.39 & 46.56 & 1.042 & 2.24 & & & & & & \\
\hline PUPAL SPOT & 26.99 & 1.087 & 4.03 & 26.68 & 1.068 & 4.00 & & & & & & \\
\hline CORE SCALES & 3.246 & 1.756 & 54.08 & 3.457 & 1.928 & 55.77 & 3.055 & 1.758 & 57.55 & 3.292 & 1.983 & 60.25 \\
\hline SCATTER SCALES & 2.880 & 1.669 & 57.93 & 3.079 & 1.862 & 60.48 & 3.521 & 1.862 & 52.88 & 3.950 & 2.227 & 56.38 \\
\hline TOTAL SCALES & 3.807 & 1.829 & 48.05 & 4.025 & 2.086 & 51.48 & 4.077 & 2.034 & 49.89 & 4.470 & 2.377 & 53.18 \\
\hline
\end{tabular}

corrected for trait size these differences were small and not significant (Table 3 ).

\section{Relationship with quality}

The individuals that died in the pupal stage had on average a slightly smaller HAUSTELLUM $(0.451 \mathrm{~mm})$ than crippled or healthy adults $(0.460$ and $0.463 \mathrm{~mm})$. This difference was not significant (ANOVA: $F_{2,265}=2.459, P=0.088$ ), and mainly caused by a few individuals of very small overall size. No significant difference in PUPAL SPOT between the health categories was detected either $\left(F_{2,254}=0.324\right.$, $P=0.72)$. No differences in FA were detected for the HAUSTELLUM (ANOVA: $F_{2,265}=0.928$, $P=0.40$ ) or the PUPAL SPOT (ANOVA: $F_{2,254}=0.007, P=0.99$ ).

The number of scales did not differ between crippled adults and adults with fully expanded wings ( $t$-tests: $P=0.36-0.90)$. The regression lines of FA on trait size were very similar for crippled and healthy adults (e.g. for TOTAL SCALES for healthy and crippled adults, respectively: slopes 0.54 and 0.52 , intercepts -0.14 and -0.10 ). No significant differences in FA were present between healthy and crippled adults (CORE SCALES: $t=0.118$, $P=0.91$; SCATTER SCALES: $t=0.181, P=0.86$; TOTAL SCALES: $t=0.326, P=0.74$ ).

\section{Genetic effects}

Both CORE and SCATTER SCALES had a large genetic component. The lowest $h^{2}$ s were found for CORE SCALES in the field but these were still highly significant (Table 4). The other $h^{2}$ s ranged from 0.72 to well above 1 . Estimates above one were caused by negative estimates of $V_{\mathrm{R}}$ and reflect the imprecise nature of quantitative genetics. The estimates for the pupal trait sizes were clearly lower. That for the HAUSTELLUM of the males was not significantly different from 0 .

The effect of family on FA tested in a one-way ANOvA was significantly different from 0 for HAUSTELLUM. The family effect for all the other asym-

Table 3 ANOvAs for the effects of sex and environment on trait sizes and fluctuating asymmetry in Inachis io. Degrees of freedom always one except for error which is 214 for pupal traits and 372 for adult traits. Asymmetry of adult traits corrected for size

\begin{tabular}{|c|c|c|c|c|c|c|c|c|c|c|c|}
\hline & & \multicolumn{3}{|c|}{ Sex } & \multicolumn{3}{|c|}{ Environment } & \multicolumn{3}{|c|}{ Sex $\times$ environment } & \multirow[b]{2}{*}{ Error } \\
\hline & & MS & $F$ & $P$ & MS & $F$ & $P$ & MS & $F$ & $P$ & \\
\hline \multirow[t]{2}{*}{ HAUSTELLUM } & Trait size & 115.46 & 7.67 & 0.0061 & & & & & & & 15.05 \\
\hline & FA & 0.05 & 0.15 & 0.703 & & & & & & & 0.33 \\
\hline \multirow[t]{2}{*}{ PUPAL SPOT } & Trait size & 2.31 & 0.14 & 0.713 & & & & & & & 17.02 \\
\hline & FA & 0.02 & 0.06 & 0.809 & & & & & & & 0.33 \\
\hline \multirow[t]{2}{*}{ CORE SCALES } & Trait size & 4.47 & 13.37 & $<0.0001$ & 2.84 & 8.50 & 0.0037 & 0.02 & 0.05 & 0.826 & 0.33 \\
\hline & FA & 0.90 & 1.54 & 0.215 & 1.04 & 1.77 & 0.185 & 0.04 & 0.06 & 0.810 & 0.59 \\
\hline \multirow[t]{2}{*}{ SCATTER SCALES } & Trait size & 8.77 & 9.61 & 0.0021 & 51.14 & 56.06 & $<0.0001$ & 1.20 & 1.31 & 0.254 & 0.91 \\
\hline & FA & 1.61 & 2.35 & 0.137 & 0.45 & 0.65 & 0.430 & 0.10 & 0.14 & 0.713 & 0.69 \\
\hline \multirow[t]{2}{*}{ TOTAL SCALES } & Trait size & 8.46 & 15.91 & $<0.0001$ & 11.60 & 21.83 & $<0.0001$ & 0.70 & 1.31 & 0.200 & 0.53 \\
\hline & FA & 1.64 & 2.29 & 0.131 & 0.26 & 0.36 & 0.555 & 0.002 & 0.002 & 0.968 & 0.72 \\
\hline
\end{tabular}


Table 4 Genetics of trait sizes and asymmetry in Inachis io. MS, $F$ and $P$ : results of one-way Anovas for family. Asymmetry of adult traits corrected for size. $V_{\mathrm{A}}$, additive variance component; $V_{\mathrm{R}}$, residual variance component; $h^{2}$, heritability; all estimated from full-sib analyses by REML procedures

\begin{tabular}{|c|c|c|c|c|c|c|c|c|c|c|c|c|c|c|}
\hline & & \multicolumn{6}{|c|}{$\begin{array}{c}\text { Males (trait size); males }+ \text { females } \\
\text { (FA) }\end{array}$} & \multicolumn{6}{|c|}{ Females (trait size) } & \\
\hline & & MS & $F$ & $P$ & $V_{\mathrm{A}}$ & $V_{\mathrm{R}}$ & $h^{2}$ & MS & $F$ & $P$ & $V_{\mathrm{A}}$ & $V_{\mathrm{R}}$ & $h^{2}$ & \\
\hline \multirow[t]{2}{*}{ HAUSTELLUM } & Trait size & 62.85 & 1.460 & 0.156 & 1.81 & 10.29 & $0.149 \mathrm{NS}$ & 40.87 & 4.13 & $* * *$ & 6.56 & 6.95 & 0.486 & $* * *$ \\
\hline & FA & 0.70 & 2.280 & 0.014 & 0.05 & 0.30 & $0.155 \mathrm{NS}$ & & & & & & & \\
\hline \multirow[t]{2}{*}{ PUPAL SPOT } & Trait size & 54.81 & 2.430 & 0.011 & 4.74 & 11.88 & $0.285 * *$ & 56.09 & 2.37 & 0.011 & 13.88 & 12.08 & 0.243 & ** \\
\hline & FA & 0.21 & 0.630 & 0.840 & -0.02 & 0.37 & $-0.049 \mathrm{NS}$ & & & & & & & \\
\hline \multirow[t]{3}{*}{ CORE SCALES } & T-size Lab & 1.37 & 6.45 & $* * *$ & 0.22 & 0.14 & $0.614^{* * *}$ & 1.701 & 11.35 & $* * *$ & 0.14 & 0.002 & 0.993 & $* * *$ \\
\hline & T-size Field & 0.83 & 2.83 & $* * *$ & 0.27 & 0.27 & $0.507^{* * *}$ & 1.49 & 4.81 & $* * *$ & 0.31 & 0.20 & 0.613 & $* * *$ \\
\hline & FA & 0.44 & 0.740 & $0.734-$ & -0.03 & 0.74 & $-0.034 \mathrm{NS}$ & & & & & & & \\
\hline \multirow[t]{3}{*}{ SCATTER SCALES } & S T-size Lab & 3.87 & 6.68 & $* * *$ & 0.64 & 0.25 & $0.721 * * *$ & 1.75 & 9.09 & $* * *$ & 0.80 & 0.06 & 0.893 & $* * *$ \\
\hline & T-size Field & 5.93 & 6.98 & $* * *$ & 1.03 & 0.10 & $0.946^{* * *}$ & 4.541 & 12.24 & $* * *$ & $1.01-$ & -0.13 & 1.153 & $* * *$ \\
\hline & FA & 1.08 & 1.620 & 0.072 & 0.02 & 0.68 & $0.029 \mathrm{NS}$ & & & & & & & \\
\hline \multirow[t]{3}{*}{ TOTAL SCALES } & T-size Lab & 2.13 & 7.26 & $* * *$ & 0.38 & 0.12 & $0.766^{* * *}$ & 2.591 & 11.69 & $* * *$ & 0.47 & 0.04 & 0.945 & $* * *$ \\
\hline & T-size Field & 3.541 & 10.14 & $* * *$ & 0.66 & -0.01 & $1.015^{* * *}$ & & 4.321 & 14.86 & $* * *$ & 0.85 & -0.12 & $1.169^{* * *}$ \\
\hline & FA & 0.58 & 0.800 & 0.670 & 0.002 & 0.82 & $0.003 \mathrm{NS}$ & & & & & & & \\
\hline
\end{tabular}

$* P<0.05, * * P<0.01, * * * P<0.001$.

metries was not significant. All of the $h^{2}$ estimates for the FA of traits were not significant, and all, except HAUSTELLUM (0.155), were very close to 0 (Table 4).

Genetic relationship with quality, environment and sex

Family mean correlations between survival and asymmetry ranged from -0.33 to 0.21 and none was significant (Table 5). The highest estimate was with HAUSTELLUM, the lowest with SCATTER
SCALES. This picture did not change drastically when the sexes were analysed separately.

The interactions between family and environment in an ANOVA for the four families that were raised in both the laboratory and the field were not significant for the adult traits, although there were family and environmental effects on the trait sizes themselves. This indicates that the effect of the growth environment was equal for all families and had no heritable component. For the asymmetries, none of the effects of environment, family or their interactions was significant for any of the traits.

Table 5 Genetic (family mean) correlation between survival and asymmetry in Inachis io. Total asymmetry is the sum of the standardized asymmetry of the individual traits

\begin{tabular}{|c|c|c|c|c|c|c|}
\hline & \multicolumn{2}{|c|}{ Total } & \multicolumn{2}{|c|}{ Male } & \multicolumn{2}{|c|}{ Female } \\
\hline & $r$ & $P$ & $r$ & $P$ & $r$ & $P$ \\
\hline \multicolumn{7}{|l|}{ Pupal traits } \\
\hline HAUSTELLUM & 0.21 & 0.522 & -0.11 & 0.743 & 0.47 & 0.15 \\
\hline PUPAL SPOT & 0.03 & 0.941 & -0.06 & 0.852 & -0.01 & 0.967 \\
\hline \multicolumn{7}{|l|}{ Adult traits } \\
\hline CORE SCALES & -0.06 & 0.859 & -0.12 & 0.720 & -0.21 & 0.530 \\
\hline SCATTER SCALES & -0.33 & 0.319 & -0.23 & 0.494 & -0.10 & 0.778 \\
\hline TOTAL SCALES & -0.26 & 0.420 & -0.25 & 0.456 & -0.50 & 0.110 \\
\hline \multicolumn{7}{|l|}{ Total asymmetry } \\
\hline FA & -0.05 & 0.887 & -0.17 & 0.629 & 0.07 & 0.839 \\
\hline
\end{tabular}




\section{Correlations}

The phenotypic correlation between the size of the two pupal traits was low and not significantly different from 0 , whereas the correlation between the size of the adult traits was positive and highly significant (Table 6). The correlations between HAUSTELLUM and the adult trait sizes were positive and significant, those between the pupal spot and the adult trait sizes slightly and nonsignificantly negative.

The genetic correlation between the pupal trait sizes was strongly negative and highly significant, indicating that the expected allometric relationship between the two trait sizes was purely environmental and countered by the negative genetic correlation. The genetic correlation between the adult trait sizes was strong and positive. The genetic correlations between the pupal traits and the adult traits were similar to the phenotypic correlations, but only one (HAUSTELLUM-SCATTER SCALES) was significant.

The phenotypic correlations between the FA of the traits were all close to and not significantly different from zero, except for the rather low correlation between the two adult traits. The genetic correlations could not be estimated reliably, because most $V_{\mathrm{A}} \mathrm{s}$ were negative or very close to 0 . When one, or both, of the $V_{\mathrm{A}} \mathrm{s}$ of two traits is zero the genetic correlation is also zero (Falconer, 1989). Genetic correlations could be calculated for the two pairs of traits for which both the $V_{\mathrm{A}} \mathrm{s}$ for FA were positive. They were not significantly different from 0 , although rather strong (even unrealistically high for one of the two), a feature common to estimates of correlations with one or both of the variances equal to or very close to 0 (Windig, 1997).

\section{Discussion}

In this study of FA of wing and pupal traits virtually no positive results were found. There was no relationship between FA and environment, one measure of quality, sex or FA of other traits. $V_{\mathrm{A}} \mathrm{s}$ and $h^{2} \mathrm{~s}$ of FA were close to and not significantly different from 0 , except perhaps for the HAUSTELLUM. It is remarkable that the family mean correlations of FA of males and females were low and not significant $(-0.17$ to 0.03$)$ except for the HAUSTELLUM (0.34). For the trait sizes these correlations were higher (0.49-0.96) and the lowest one was for the HAUSTELLUM.

\section{Genetic effects}

The $h^{2}$ of FA is a controversial subject. Møller \& Thornhill (1997) listed studies that report $h^{2}$ of developmental stability. The average $h^{2}$ of FA in

Table 6 Phenotypic and genetic correlations for Inachis io. Below diagonal: correlations between trait sizes; above diagonal: correlations between asymmetry of traits. Genetic correlations calculated from covariances and variances in REML analyses. Significance of genetic correlations tested on covariances. $\mathrm{x}$, not calculated because of dependency of traits. $0^{\mathrm{a}}$, set to 0 because of negative or 0 variances

\begin{tabular}{|c|c|c|c|c|c|}
\hline & \multicolumn{2}{|c|}{ Pupal traits } & \multicolumn{3}{|c|}{ Adult traits } \\
\hline & $\begin{array}{l}\text { HAUSTEL- } \\
\text { LUM }\end{array}$ & $\begin{array}{l}\text { PUPAL } \\
\text { SPOT }\end{array}$ & $\begin{array}{c}\text { CORE } \\
\text { SCALES }\end{array}$ & $\begin{array}{c}\text { SCATTER } \\
\text { SCALES }\end{array}$ & $\begin{array}{r}\text { TOTAL } \\
\text { SCALES }\end{array}$ \\
\hline \multicolumn{6}{|l|}{ Phenotypic } \\
\hline HAUSTELLUM & - & 0.03 & 0.004 & 0.07 & -0.01 \\
\hline PUPAL SPOT & 0.01 & - & 0.04 & 0.02 & 0.08 \\
\hline CORE SCALES & $0.25 * * *$ & -0.10 & - & $0.11^{*}$ & $\mathrm{x}$ \\
\hline SCATTER SCALES & $0.15^{*}$ & -0.10 & $0.58 * * *$ & - & $\mathrm{x}$ \\
\hline TOTAL SCALES & $0.20 * * *$ & -0.10 & $\mathrm{x}$ & $\mathrm{x}$ & - \\
\hline \multicolumn{6}{|l|}{ Genetic } \\
\hline HAUSTELLUM & - & $0^{\mathrm{a}}$ & $0^{\mathrm{a}}$ & -0.67 & 4.53 \\
\hline PUPAL SPOT & $-1.21 * * *$ & - & $0^{\mathrm{a}}$ & $0^{\mathrm{a}}$ & $0^{\mathrm{a}}$ \\
\hline CORE SCALES & 0.19 & -0.25 & - & $0^{\mathrm{a}}$ & $\mathrm{x}$ \\
\hline SCATTER SCALES & $0.49 *$ & -0.31 & $0.84 * * *$ & - & $\mathrm{x}$ \\
\hline TOTAL SCALES & 0.27 & -0.27 & $\mathrm{x}$ & $\mathrm{x}$ & - \\
\hline
\end{tabular}


these studies ranged from -0.02 to 1.072. Apart from three outliers, which were thought to be incorrect by Leamy (1997), Palmer \& Strobeck (1997) and Whitlock \& Fowler (1997), the estimates of $h^{2}$ of FA were all rather low $(<0.35)$. The results of this study, no $h^{2}$ of FA or a rather low nonsignificant $h^{2}$ of 0.15 , are quite similar to many other studies, and add to the doubts of the generality of a heritable basis of FA (Palmer \& Strobeck, 1986; Markow \& Clarke, 1997).

One of the main concerns of the commentaries published in the same issue as Møller \& Thornhill (1997) was that most studies did not meet the requirements for a rigorous investigation of the $h^{2}$ of FA. This study meets three of the requirements:

1 the asymmetry was larger than the measurement error (Table 1);

2 the asymmetry concerned FA (Table 1, Fig. 2);

3 in those traits where there was an effect of size, it was removed (Fig. 2).

The fourth criterion was not met. The analysis was a full-sib analysis and $V_{\mathrm{A}}$ thus includes part of $V_{\mathrm{D}}$, maternal effects and common environmental effects. This price has to be paid in order to say something about genetics in the field. For the adult traits and the PUPAL SPOT this is a small price. The estimated $V_{\mathrm{A}}$ is negative or very close to 0 even with the other effects included. Only the $h^{2}$ of FA for the HAUSTELLUM is possibly an overestimate, though one cannot attach too much value to this estimate because it also was not significantly different from 0 .

Huge sample sizes are needed to obtain significant $h^{2} \mathrm{~s}$ if they are small as is expected for $h^{2} \mathrm{~s}$ of FA. From the $h^{2}$ s for trait sizes it can be seen that $h^{2} \mathrm{~S}$ below 0.20 do not give significant results. Significant results are easier obtained with ANOVAs testing for differences between the means of families, although this is less accurate because family means also contain residual variance. Power calculations indicate that for the sample sizes used here, a $h^{2}$ of 0.029 or higher would give significant results at the 5 per cent level, and $h^{2}$ s of 0.02 or higher at a 10 per cent significance level. Thus the $h^{2} \mathrm{~s}$ for the FA of the traits analysed here, except the HAUSTELLUM, were at least smaller than 0.03 and possibly considerably smaller than that. Genetic correlations are usually even harder to estimate reliably, especially if they are small (Windig, 1997). The construction of reliable G-matrices for FA as a measure of overall developmental stability in a population (Swaddle, 1997) will thus in most cases be impossible, as it was in this study.

Several authors have stated that estimating a single, global value for $h^{2}$ of FA is not of much interest. Instead it would be much more interesting to compare the $h^{2}$ of FA of different categories of traits (Leamy, 1997; Markow \& Clarke, 1997; Palmer \& Strobeck, 1997; Pomiankowski, 1997). One can make several suggestions which kind of traits will have a FA that shows a relationship with quality, and will have a relatively higher $h^{2}$. The idea cited most often is that secondary sexual characters reflect quality and will have a higher $h^{2}$ of FA (Møller \& Pomiankowski, 1993). In the present study only the adult traits may be involved in sexual communication, but this seems doubtful. There was a large overlap between male and female traits, and there is no indication at all that eyespots can be used in sexual communication (Silberglied, 1984).

The $h^{2}$ of FA is probably related to the amount of residual variance $\left(V_{\mathrm{R}}\right)$ in a trait. Gavrilets \& Hastings (1994) consider both a measure of developmental instability. Delpuech et al. (1995) compared FA and $V_{\mathrm{R}}$ across a range of temperatures and found them to agree. Generally a relatively higher $V_{\mathrm{R}}$ will result in a lower $h^{2}$. In this respect it is interesting that the only trait that had a slightly higher $h^{2}$ for its FA in this study, the HAUSTELLUM, also had a low $h^{2}$ of trait size compared with the other traits. The suggestion of Pomiankowski (1997) to compare the $h^{2}$ of FA with the $h^{2}$ of trait sizes thus seems interesting.

Traits involved in plasticity may have larger amounts of FA. Genotypes form a different phenotype for plastic traits in different environments. This may have as a consequence that it is not possible to form exactly one phenotype, precisely matched between left and right within each environment. In this study the PUPAL SPOT was the trait that showed greatest plasticity. On a darker background pupae are darker (Brecher, 1923) with larger spots. There is also some plasticity involved in the adult traits as can be seen by comparing the field and laboratory values (Tables 2 and 3). Only the HAUSTELLUM does not seem to be plastic.

Information on the developmental pathways of traits will probably help most to understand why FA and its $h^{2}$ differs between traits. The development of eyespots in butterfly wings has been well studied (Nijhout, 1991; Brakefield et al., 1996). The basic model for eyespot development is a gradient in a 'morphogen' from the eyespot centre ('focus' or 'pupil') to the surrounding cells. Concentrations of morphogen above or below a certain value result in the deposition of different pigments in the scales. If the concentration is exactly at this value it will be a matter of chance which pigment is formed. Spots without a sharp border between one colour and the 
other, like the blue spots investigated here, can be explained by the model if the morphogen gradient is very shallow, or if there is a range of morphogen concentrations, instead of a single value, that separates the two colours. If this model is correct there is a lot of chance involved in which scales are formed, and FA is thus large with little scope for a relationship with anything else than chance. The FA was remarkably high for the spots here ( $>50$ per cent) compared with what is generally found $(<1$ per cent according to Palmer \& Strobeck, 1997; $<5$ per cent according to Pomiankowski, 1997).

Asymmetry itself may have consequences on fitness. In this study this seems probable for the HAUSTELLUM. The two parts of the HAUSTELLUM cover the parts from which the proboscis (the 'tongue' of the adults) is formed. Symmetry in these parts is probably essential for a good match in order to fuse the parts together. The PUPAL SPOT probably enhances the crypsis of pupae, either by disrupting the shape of the pupa or by matching the background colour of the pupation site. Any functional significance of asymmetry in the PUPAL SPOT seems unlikely. If anything asymmetry will decrease the recognizability of pupae for predators, rather than increase it. The blue scales form part of a large eyespot, the most likely function of which is to startle predators by being exposed suddenly when the wings are flashed open. Variation in neither the number of blue scales nor asymmetry seems likely to influence this function to a great extent.

The assumption that FA is directly related to the quality of an individual was not confirmed in this study, although the measurement of quality (and environment) was rather crude. Moreover there seems to be only a weak (HAUSTELLUM) or no (the other traits) genetic basis for FA, which indicates that evolution of FA can be at best very slow. So both a relationship of FA with fitness and with genotype seems doubtful. Before measures of FA can be used in any evaluation of quality of individuals a test whether (some) traits are associated with quality is essential. The results of this study underscore the call by Markow (1995) for a critical evaluation of FA.

\section{Acknow ledgements}

I am grateful to the research group on ecology and evolution of the RUCA, especially Jan Scheirs and Luc de Bruyn for hospitality and space in their climate chambers, and the use of their micrometer, and to David Currie and Pascal Lamar for help in the lab. at peak moments of butterfly emergence in midsummer. This study was supported by a grant from the EEC Human Capital and Mobility programme (contract no. ERBCHBICT941145).

\section{References}

BRAKEFIELD, P. M. AND BREUKER, C. J. 1996. The genetical basis of fluctuating asymmetry for developmentally integrated traits in a butterfly eyespot pattern. Proc. $R$. Soc. B., 263, 1557-1563.

BRAKEFIELD, P. M., GATES, J., KEYS, D., KESBEKE, F., WIJNGAARDEN, P. J., MONTEIRO, A. ET AL. 1996. The development, plasticity and evolution of butterfly eyespot patterns. Nature, 384, 236-242.

BRECHER, L. 1923. Die Puppenfärbungen der Vanessiden. Archiv. mikr. Anat. Entw., 102, 517-548.

ClARKE, G. M. 1993. The genetic basis of developmental stability. I. Relationships between stability, heterozygosity and genomic coadaptation. Genetica, 89, 15-23.

DelpueCh, J.-M., MORETEAU, B., CHICHE, J., PLA, E., VOUIDIBIO, J. AND DAVID, J. R. 1995. Phenotypic plasticity and reaction norms in temperate and tropical populations of Drosophila melanogaster: ovarian size and developmental temperature. Evolution, 49, 670-675.

FALCONER, D. S. 1989. Introduction to Quantitative Genetics, 3rd edn. Longman, Harlow.

FOWLER, K. AND WHITLOCK, M. C. 1994. Fluctuating asymmetry does not increase with moderate inbreeding in Drosophila melanogaster. Heredity, 73, 373-376.

GAVRILETS, S. AND HASTINGS, A. 1994. A quantitative genetic model for selection on developmental noise. Evolution, 48, 1478-1486.

LEAMY, L. 1997. Is developmental stability heritable? J. Evol. Biol., 10, 21-29.

MARKOW, T. A. 1995. Evolutionary ecology and developmental instability. Ann. Rev. Ent., 40, 105-120.

MARKOW, T. A. AND CLARKE, G. M. 1997. Meta-analysis of the heritability of developmental stability: a giant step backward. J. Evol. Biol., 10, 31-37.

MATHER, K. 1953. Genetic control of stability in development. Heredity, 7, 297-336.

MøLler, A. P. 1994. Sexual selection in the barn swallow (Hirundo rustica). IV. Patterns of fluctuating asymmetry and selection against asymmetry. Evolution, 48, 658-670.

MØLLER, A. P. 1995. Leaf mining insects and fluctuating asymmetry in elm Ulmus glabra leaves. J. Anim. Ecol., 64, 697-707.

Møller, A. P. AND POMIANKOWSKI, A. 1993. Fluctuating asymmetry and sexual selection. Genetica, 89, 267-297.

MøLLER, A. P. AND THORNHILL, R. 1997. A meta-analysis of the heritability of developmental stability. J. Evol. Biol., 10, $1-16$.

NiJhout, H. F. 1991. The Development and Evolution of Butterfly Wing Patterns. Smithsonian Inst. Press, Washington, D.C.

PALMER, A. R. 1994. Fluctuating asymmetry analyses: a primer. In: Markow, T. A. (ed.) Developmental 
Instability: Its Origins and Evolutionary Implications, pp. 358-364. Kluwer, Dordrecht.

PAlMER, A. R. AND STROBECK, C. 1986. Fluctuating asymmetry: measurement, analysis, patterns. Ann. Rev. Ecol. Syst., 17, 391-421.

PALMER, A. R. AND STROBECK, C. 1997. Fluctuating asymmetry and developmental stability: heritability of observable causes vs. heritability of inferred cause. $J$. Evol. Biol., 10, 39-49.

PARSONS, P. A. 1990. Fluctuating asymmetry: an epigenetic measure of stress. Biol. Rev., 65, 131-145.

POMIANKOWSKI, A. 1997. Genetic variation in fluctuating asymmetry. J. Evol. Biol., 10, 51-55.

PULLIN, A. s. 1986. Influence of the foodplant Urtica dioica on larval development, feeding efficiencies and voltinism of a specialist insect Inachis io. Hol. Ecol., 9, 72-78.

SACCHERI, I. J. AND BRUFORD, M. W. 1994. DNA fingerprinting in a butterfly (Bicyclus anynana). J. Hered., 84, 195-200.

SHAW, R. G., PLATENKAMP, G. A. J., SHAW, F. H. AND PODOLSKY, R. H. 1995. Quantitative genetics of response to competitors in Nemophila menziessi: a field experiment. Genetics, 136, 397-406.

SILBERGLIED, R. E. 1984. Visual communication and sexual selection in butterflies. In: Vane-Wright, R. I. and Ackery, P. R. (eds) The Biology of Butterflies, pp. 207-223. Academic Press, London.

SWADDLE, J. P. 1997. On the heritability of developmental stability. J. Evol. Biol., 10, 57-61.

UENO, H. 1994. Fluctuating asymmetry in relation to two fitness components, adult longevity and male mating success in a ladybird beetle, Harmonia axyridis (Coleoptera: Coccinellidae). Ecol. Entomol., 19, 87-88.

WAUTERS, L. A., DHONDT, A. A., KNOTHE, H. AND PARKER, D. т. 1996. Fluctuating asymmetry and body size as indicators of stress in red squirrel populations in woodland fragments. J. Appl. Ecol., 33, 735-750.

WHITLOCK, M. C. AND FOWLER, K. 1997. The instability of studies of instability. J. Evol. Biol., 10, 63-67.

wINDIG, J. J. 1997. How to calculate genetic correlations across environments? J. Evol. Biol., 10, 853-874. 